\title{
Design and Development of a Bus Stop Inventory to Support an Intelligent Transportation System: The MARTA Experience
}

\author{
Wayne Sarasua \\ Georgia Institute of Technology \\ Robert Awuah-Baffour \\ Bradley University \\ Mark Fawley \\ $T R W$ \\ Carlton Byars \\ MARTA \\ Jeffery Orton \\ Utah Transit Authority \\ $\overline{\text { Abstract }}$
}

Bus stops are a critical element in any transit system. The advent of Intelligent Transportation System (ITS) technologies in the area of transit has developed a need for transit agencies to keep an up-to-date inventory of bus stop data. Unfortunately, 
most transit agencies do not have a bus stop inventory that can adequately support Advanced Public Transportation System (APTS) applications, and many other transit agencies do not have an inventory at all. The design, development, and maintenance of a bus stop inventory that will support an array of available APTS applications is described in this paper. Procedures used in the development of the Metropolitan Atlanta Rapid Transit Authority bus stop inventory are highlighted. The lessons learned from MARTA's experience should be valuable to other transit agencies that are planning to or are in the process of implementing an APTS.

\section{Introduction}

In the spring of 1995, the Metropolitan Atlanta Rapid Transit Authority (MARTA) contracted with a team of consultants and researchers to implement an Intelligent Transportation System (ITS). The purpose of this system was to create a showcase of technology for the 1996 Summer Olympic Games and to leave MARTA with a legacy that would improve transit performance and increase ridership in the long term. The project put in place at MARTA three areas of technology: 1) Advanced Traveller Information Systems (ATIS) that provide an automated means of assisting MARTA patrons with travel information, 2) Automatic Vehicle Location (AVL) for tracking bus positions in real time, and 3) an interface with Georgia Department of Transportation's Advanced Transportation Management System (ATMS) so that up-to-date traffic and road condition information could be made available to MARTA.

At the core of the MARTA ITS is a series of spatial and attribute databases that provides critical information to all of the different ITS applications. One of the transit features that is described in these databases is the bus stop. Bus stop data are of particular importance to the MARTA ITS because they are used by so many different applications. The attribute data associated with each bus stop is as extensive as any other bus stop inventory that currently exists in the United States. The database contains more than 60 fields that provide detailed location information and the physical characteristics of the bus stop and the surrounding area. 
This paper describes the design, development, and maintenance of the bus stop inventory that supports MARTA's ITS. The procedures described in this paper should be applicable to other transit agencies implementing systems that fall under the Federal Transit Administration's Advanced Public Transportation Systems (APTS) Program (Casey et al. 1996).

\section{APTS Applications Supported by a Bus Stop Inventory}

The design of a bus stop inventory database is driven by the applications that it will need to support. The two primary ITS applications that depend on bus stop information at MARTA are:

- $\quad$ ATIS, which provides an automated means of assisting MARTA patrons with travel information, and

- AVL which provides real-time bus locations.

Bus stops are fundamental to the MARTA ATIS. MARTA's ATIS provides a patron with an itinerary that includes a description of the bus stops at the beginning and end of a trip, as well as bus stops at any transfer points. MARTA has found that many patrons ask specific information about bus stops such as whether or not the bus stop is sheltered or lighted or if the stop is wheelchair accessible. These attributes, as well as many others, are available to the patron through the ATIS. Bus stops are also an important component of the AVL. As a bus nears a particular bus stop, the on-board Global Positioning System (GPS) provides a central computer with the bus location. This location is matched with a bus stop through coordinate matching. Details of the approaching bus stop are relayed to passengers through an automated announcement. Another AVL application is automatic passenger counting. The number of passenger alightings and boardings can be matched with the corresponding bus stop using the same matching process that is used for bus stop announcements.

Several other uses of bus stop data that do not fall under the ITS umbrella include transportation planning, maintenance, and information management. 
MARTA's bus stop database includes a series of fields to support these applications as well.

\section{Bus Stop Inventory Database Design}

The considerations in designing a bus stop database include identification of fields, the types of fields (e.g., character, integer, date, etc), the size of the fields, the allowable range of values (e.g., 0 - 200), and the relationships between the bus stop table and other database tables in the overall system. Further, it may be necessary to have multiple tables to manage just the bus stop data. An example would be if a particular field has, say, six discrete choices. The bus stop type field is an example. Let us assume the possible values for the bus stop type field are post, strap sign, pedestal sign, shelter, paint, and station. If the inventory procedures require typing in a value for the field, it may be preferable to use a code $(1,2,3,4,5$, or 6$)$ to represent the above choices. Thus, the user would simply have to type in " 3 " rather than "pedestal sign" for each bus stop of this type. This example can be managed in a relational database by creating a separate table that includes the codes and associated descriptions. A relational join could then be set up between the master bus stop table containing only the codes and the separate table containing the code definitions.

The database that supports the MARTA ITS applications includes more than 30 relational tables. Twelve of these tables are at least partially maintained within the Geographical Information System (GIS). Figure 1 provides an EntityRelationship (E-R) diagram of these tables. The largest of the tables shown in Figure 1 is the stop master table, which contains the bus stop data. This table currently includes 66 fields and more than 10,000 records. An identification number (stop ID) serves as a unique key that makes it possible to link bus stop data with data in other tables, such as those associated with time points and routes.

Table 1 provides a list of 36 fields that pertain to the actual field inventory. The inventoried fields in the stop master table include identification fields, coordinate fields, street location fields, fields describing the physical characteristics of the bus stop, and fields describing the surrounding area. The stop master table 


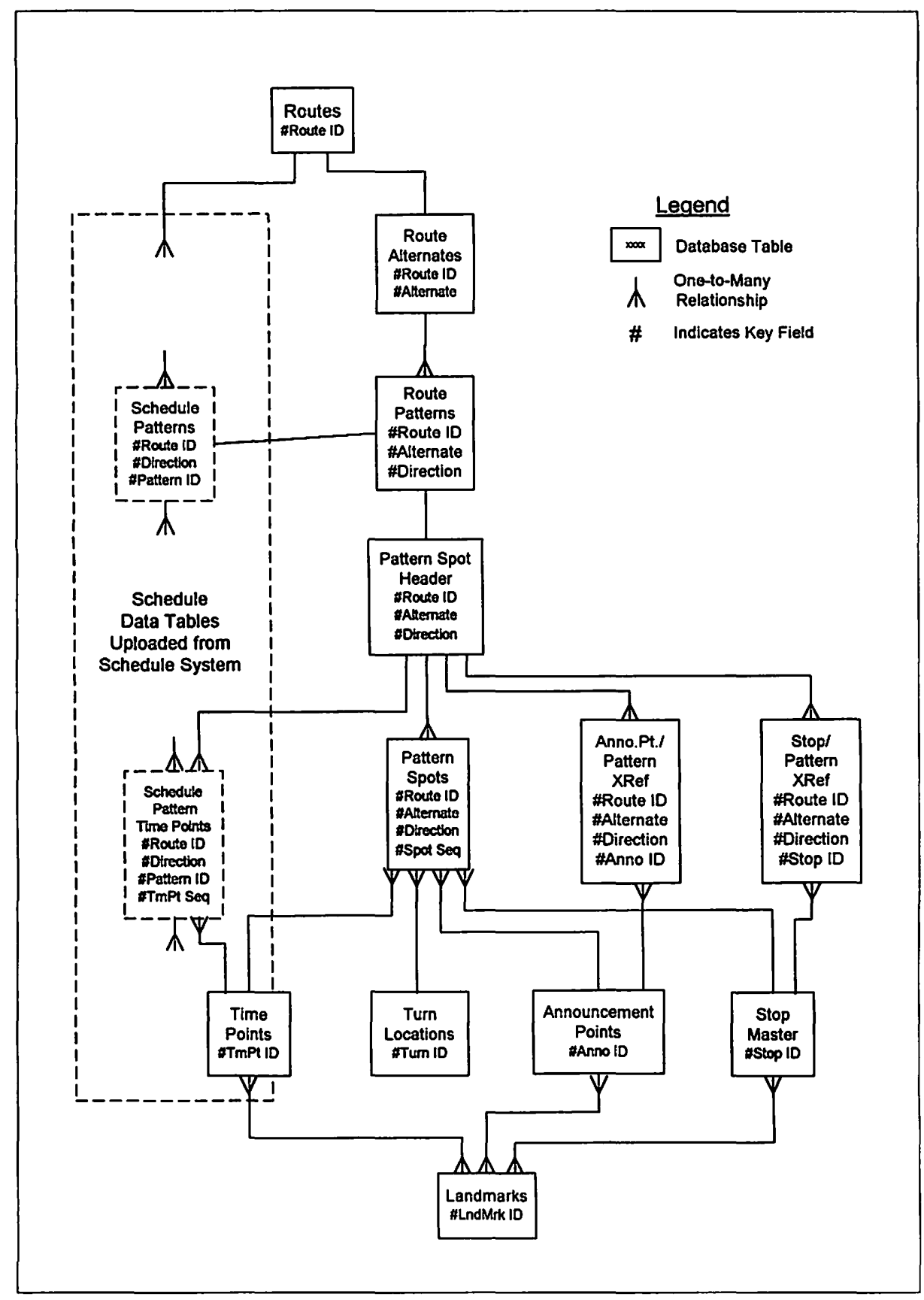

Figure 1. Entity-relationship diagram of GIS-maintained tables. 


\section{Table 1}

\section{Bus Stop Inventory Database Contents}

\begin{tabular}{|c|c|c|}
\hline Field & WidthType & Description \\
\hline stop_id & 8 chars & $\begin{array}{l}\text { Unique ID for each bus stop, based on grid cell } \\
\text { location. }\end{array}$ \\
\hline description & 35 chars & Description of where the bus stop is located. \\
\hline building_no & 10 chars & $\begin{array}{l}\text { Address of the bus stop on the "on" street (requires } \\
\text { AT or OP). }\end{array}$ \\
\hline on_street_prefix & 2 chars & $\begin{array}{l}\text { Prefix of the street the bus stop is on (values: N, S, } \\
E, W \text { ). }\end{array}$ \\
\hline on_street_name & 20 chars & Street name where bus stop is located. \\
\hline on_street_type & 4 chars & $\begin{array}{l}\text { Type of street the bus stop is on (e.g., Ave., Dr., } \\
\text { etc.) }\end{array}$ \\
\hline on_street_suffix & 2 chars & $\begin{array}{l}\text { Suffix of the street the bus stop is on (values: N, S, } \\
E, W \text { ). }\end{array}$ \\
\hline on_street_dir & 2 chars & $\begin{array}{l}\text { Direction of travel of the "on" street (values: N, W, } \\
E, W, N E, N W, S E \text {, or SW. }\end{array}$ \\
\hline intersection_pos & 2 chars & $\begin{array}{l}\text { Position on the "on" street relative to the "at" street } \\
\text { (values: NS, FS, MB, AT, OP). }\end{array}$ \\
\hline at_street_prefix & 2 chars & Prefix of the "at" street which the bus stop is near. \\
\hline at_street_name & 20 chars & Name of the "at" street which the bus stop is near. \\
\hline at_street_type & 4 chars & $\begin{array}{l}\text { Type of the "at" street which the bus stop is near } \\
\text { (similar to on_street_prefix). }\end{array}$ \\
\hline at_street_suffix & 2 chars & $\begin{array}{l}\text { Suffix of the "at" street field which the bus stop is } \\
\text { near (similar to on_street_type). }\end{array}$ \\
\hline bet_street_prefix & 2 chars & $\begin{array}{l}\text { Prefix of the between street which the bus stop is } \\
\text { near. }\end{array}$ \\
\hline bet_street_name & 20 chars & Name of between street which the bus stop is near. \\
\hline bet_street_type & 4 chars & Type of between street which the bus stop is near. \\
\hline bet_street_suffix & 2 chars & $\begin{array}{l}\text { Suffix of the between street which the bus stop is } \\
\text { near. }\end{array}$ \\
\hline dist_from_at_st & Small int & $\begin{array}{l}\text { Distance of the bus stop from the "at" street in feet } \\
\text { (values: } 0-50,50-200,>200 \text { ). }\end{array}$ \\
\hline
\end{tabular}


Table 1 (cont)

\begin{tabular}{|c|c|c|}
\hline Field & Width/Type & Description \\
\hline comment & 30 chars & $\begin{array}{l}\text { Any comment related to the bus stop. This field is } \\
\text { optional. }\end{array}$ \\
\hline ada_accessibility & 1 char & $\begin{array}{l}\text { Accessibility of bus stop by elderly persons or per- } \\
\text { sons with a disability (values: yes } Y ; \text { no } N \text { ). }\end{array}$ \\
\hline sidewalk & 2 chars & $\begin{array}{l}\text { Sidewalk? (Values: yes Y; yes but poor condition } \\
\text { YP; yes but short YS; no N). }\end{array}$ \\
\hline lift & 2 chars & Can a handicap lift be used? (values: yes $\mathrm{Y}$; no N). \\
\hline curb & 2 chars & $\begin{array}{l}\text { Curb at the bus stop? (values: yes Y; yes but not lift } \\
\text { accessible } Y N \text {; no N). }\end{array}$ \\
\hline curb_cut & 2 chars & $\begin{array}{l}\text { Denotes a curb cut (values: yes Y; no N; not appli- } \\
\text { cable NA). }\end{array}$ \\
\hline telephone & 1 char & $\begin{array}{l}\text { Nearby telephone? (values: none N; public P; busi- } \\
\text { ness B). }\end{array}$ \\
\hline park_and_ride & 1 char & $\begin{array}{l}\text { Is bus stop located at a park and ride facility? (val- } \\
\text { ues: yes Y; no N). }\end{array}$ \\
\hline bus_stop_type & 3 chars & $\begin{array}{l}\text { Bus stop type (post POS; strap STR; shelter SHM; } \\
\text { paint PNT; sign SGN). }\end{array}$ \\
\hline neighborhood & 3 chars & $\begin{array}{l}\text { Land use nearby (commercial COM; school SCH; } \\
\text { industrial IND; mix MIX). }\end{array}$ \\
\hline lighting & 1 char & $\begin{array}{l}\text { Type of lighting at the bus stop (values: dedicated } \\
D ; \text { poor P; on-street OS). }\end{array}$ \\
\hline landmark & 40 chars & The largest landmark serviced by the bus stop. \\
\hline latitude & Float & Latitude value for bus stop; collected by GPS. \\
\hline longitude & Float & Longitude value for bus stop; collected by GPS. \\
\hline collect_date & 10 chars & Date bus stop data collected. \\
\hline
\end{tabular}

includes several additional fields that are generated by the GIS and other programs that process the inventoried bus stop data. Some examples of generated data include the city, county, and zip code in which the bus stop is located. A GIS point-in-polygon operation is used to provide these data. 


\section{Assigning Unique Bus Stop Identifiers}

A unique bus stop identification scheme was needed to serve as a key to the bus stop data. Several schemes were considered, including assigning random IDs, assigning IDs by route, and using a grid cell scheme. The random ID was undesirable because there would be no logical consistency between bus stops in close proximity to one another. Assigning bus stops by using the route ID in the bus stop ID was not feasible because many bus stops serve more than one route. The scheme ultimately chosen for the MARTA ITS was a grid cell system. DeKalb and Fulton counties (the two counties served by MARTA) were divided into 200 distinct grid cells. Any bus stop falling in a particular grid cell received an ID of $X X X Y Y Y$, where $X X X$ is the cell number and $Y Y Y$ is the bus stop sequence number within each cell. The benefit of this identification scheme is that ID numbers are consistent with nearby bus stops. The grid cell system that was used for the MARTA ITS is shown in Figure 2.

\section{Cartesian and Two Sets of Geographic Coordinates}

The MARTA ITS required using three pairs of coordinate fields. To support the third party trip itinerary software, cartesian coordinate fields were needed. This was purely a function of the third-party software and may not be required for other jurisdictions. Geographic coordinates (longitude and latitude) were required to support the AVL application. These coordinates need to be reasonably accurate. This is especially important for the automated passenger counters and the bus stop announcements. The third pair of coordinates is longitude and latitude as related to the underlying base map. These may vary from the true geographic coordinates, depending on map accuracy. The need for this third pair of coordinates is discussed in the following paragraph.

Most of the bus stops in the MARTA service area are within 100 feet of an intersection and many are within a few feet of an intersection. In the collection process using differential GPS, the expected accuracy of the bus stops is within 10 feet. If the underlying GIS map at a particular intersection provides less than 20-foot accuracy, the bus stop could easily appear to be on the wrong side of the street on the GIS map. The user has one of three options: 1) do nothing; 2) edit 


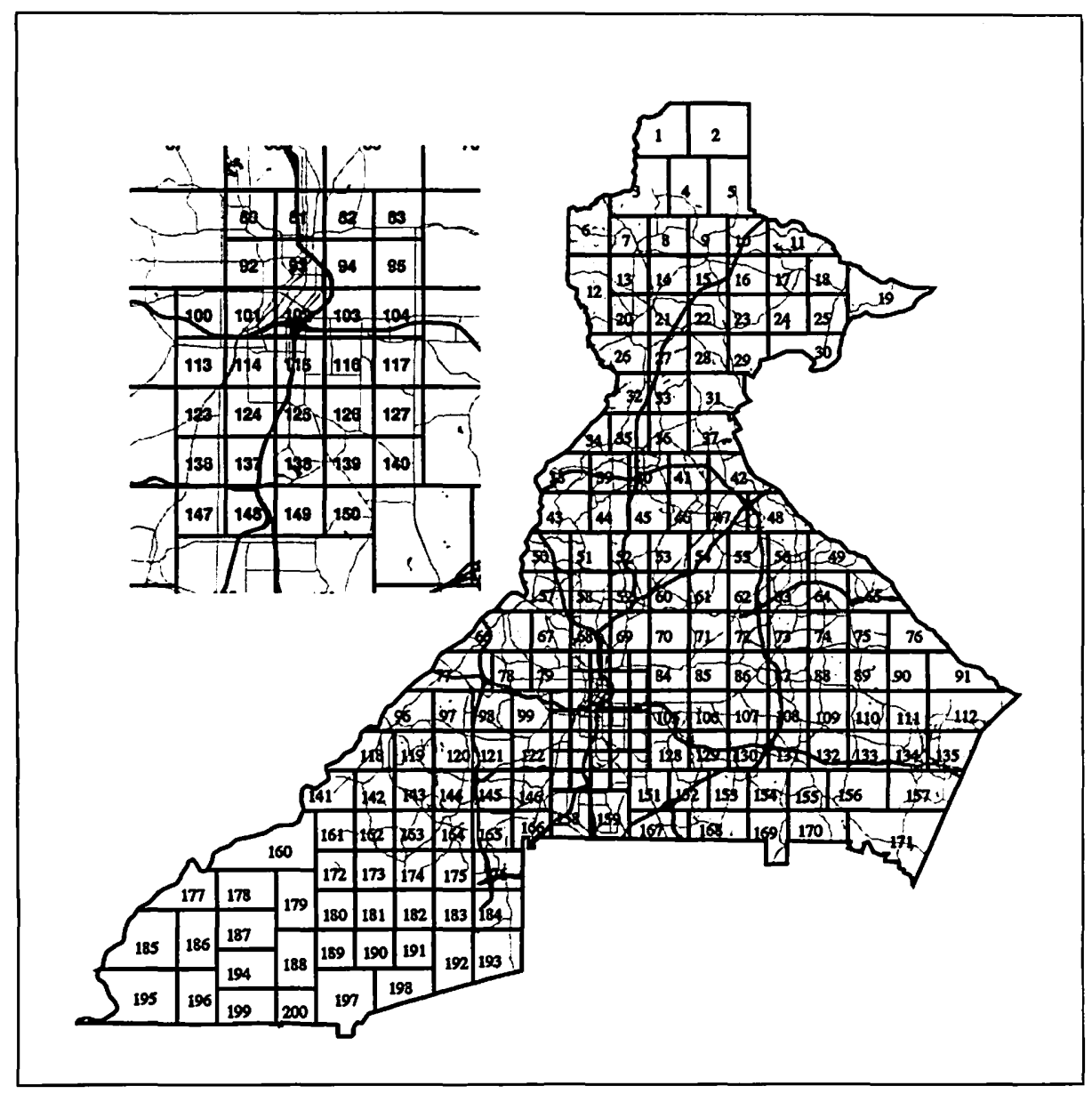

Figure 2. MARTA bus stop geocoding project: grid cell map.

the map so that the bus stop appears on the correct side of the intersection; or 3) move the bus stop in the GIS. The do-nothing alternative is not advisable for most applications. Customer service operators may direct patrons to the wrong side of the street. Work crews relying on GIS maps may not be able to find a bus stop if the map is wrong. Further, the automated tools that associate bus stops with route patterns will give incorrect associations if the bus stop is on the wrong side of the street. 
The second alternative may be preferable from an accuracy standpoint but edits to the underlying map may be difficult, especially if a commercially developed base map is used. This is the case with MARTA. While it is entirely possible for MARTA to modify the map, vendor updates to the map may not have these modifications. Thus, it is advisable to refer any changes to the underlying GIS map to the vendor. However, vendor-supplied updates may not be available in a timely manner. The third alternative involves moving the bus stop in the GIS. As long as the move is relatively small, most applications will not be affected. AVL is one exception. The annunciators and the automatic passenger counters may not relate to the correct bus stops. To account for this, it may be necessary to retain the true geographic coordinates as well as the map coordinates.

\section{A Bus Stop's Location Relative to Streets}

Coordinate locations are usually meaningless to most users of a bus stop inventory. These users rely on street descriptions to precisely locate a bus stop. The MARTA ITS uses one of four different ways to describe a bus stop's street location: address, intersection, midblock, or landmark.

For a bus stop located by address, the building number and on-street fields are populated. The intersection position field is set to "at" (at the street address) or "opposite" (across the street from the address). For bus stops at intersections, the on-street and at-street fields are populated and the intersection position field is set to nearside or farside. Midblock bus stops require an on-street, an at-street (for midblocks in the MARTA ITS, this is always the street ahead or down stream), and between-street (in the MARTA ITS, this is always the street behind or up stream). In using landmark descriptions, the location of the stop is given to the itinerary user as a landmark name. Thus, the patron is asked to board or alight a bus or train at a landmark (e.g., Lindberg Center Station) instead of an address (e.g., 2424 Piedmont Rd).

There is little debate among transit agencies that bus stops that are at the intersection (but not at a major landmark) should be described that way to cus- 
tomers. The question arises on how to describe midblock bus stops. Using the midblock technique described above could be problematic because there may be multiple midblock bus stops along a particular stretch of road. Using addresses solves this problem, but addresses are sometimes difficult to identify during a field survey. Further, address descriptions are usually less descriptive to a patron then a midblock description. For example, patrons usually find it more difficult to mentally visualize the location of the bus stop at "1040 Peachtree Street" versus the bus stop on "Peachtree Street" between "10th and 11th Streets."

\section{Physical Description of the Bus Stop}

The fields that describe the physical characteristics of the bus stop are self explanatory. One problem with these fields is that many of them are somewhat subjective. Thus, it is important that each of these fields has a set of rules to follow to minimize conflicting values between different field survey personnel. The most important of the physical description fields are those that give an indication of the accessibility of a bus stop. MARTA has several fields that relate to accessibility. Americans with Disabilities Act (ADA) compliance is one of these fields. This was found to be one of the most difficult fields to populate during the field data collection. A bus stop may have a shelter that is ADA compliant in terms of pad size, etc., but the bus stop may not be accessible because there may be little or no sidewalk leading to the stop or they may not be a nearby curb cut or handicap ramp to allow a person in a wheelchair to access the shelter.

\section{Surrounding Area}

Nearby landmarks are vital to the ATIS application. A patron usually will prefer to identify an origin or destination by a landmark name rather than an intersection or address. Thus, landmarks should be included with bus stops when possible. One problem that occurred in the creation of the MARTA bus stop inventory was that the field inventory was done simultaneously with the creation of a landmark database. In the MARTA ATIS application, the name of a landmark associated with a bus stop must exactly match a landmark name in the landmark database. This was often not the case because the bus stop field surveyors did not know what the exact landmark names would be. To avoid this 
problem, a transit agency should consider creating a landmark database prior to creating a bus stop database. Thus, a list of landmarks could be taken into the field by the bus stop surveyors to ensure that proper landmark names are used.

\section{Bus Stop Database Development}

There are several methods that could be used to geocode the location of bus stops. Surveying from known geodetic points will provide very accurate results but this method is very costly. Dead reckoning from nearby intersections is much less costly and can provide reasonable results as long as an accurate basemap is used to determined the bus stop's coordinates from the dead reckoning information. A third possibility is to use a differential GPS. A review of literature indicated that bus stops have never been inventoried using GPS prior to the development of the MARTA ITS. The successful use of GPS in similar applications such as the collection of traffic sign locations (Poling et al. 1993) and utilities delineation (Bricker and Kemmer 1995) made it evident that GPS would be viable for bus stop collection.

Because of the GPS's capability to provide instantaneous coordinate information, it was selected as the primary geocoding tool for building the MARTA bus stop inventory. It was anticipated that an alternative geocoding method would be needed in some instances because of limitations of GPS. Buildings, topography, and satellite positioning can adversely affect a GPS's ability to generate accurate coordinate information. In these instances, either dead reckoning from known points or "heads-up" digitizing on a street map displayed on a laptop computer could be used. GPS accuracy is also affected by the amount of time that the GPS is collecting coordinates at a single location. The best results are achieved by allowing the GPS to collect a minimum of 180 seconds of data. During this time, the field worker can type in associated attribute data.

For the MARTA ITS, the bus stop inventory development involved three broad tasks: 1) field survey, 2) office processing, and 3) field verification. Each of these tasks included several subtasks. Careful records were kept throughout the collection process to ensure that the final bus stop database was complete and accurate. 


\section{Field Survey}

The field survey was conducted using a notebook computer connected to a Trimble Pathfinder GPS receiver (Trimble 1991). This particular GPS receiver is capable of providing two-meter accuracy through post-process differential correction. Carrier phase surveying quality GPS receivers can provide sub-centimeter accuracy but the relative benefit of having this accuracy did not justify the additional cost of the receivers.

Specialized software was used in conjunction with the GPS to collect the bus stop data. Georesearch's Geolink product was used as the inventory software (Georesearch Inc. 1995). Geolink was chosen because it could be easily customized to collect bus stop attributes. The computer/software combination was connected to the Trimble GPS receiver and brought into the field to collect bus stop information. As data were collected by the GPS, the position of the bus stop was immediately shown on the computer display with a background map of streets serving as a position reference. The output from the GPS receiver was stored on the notebook's hard drive along with any related attribute information entered in by the surveyor. Each individual piece of data was automatically time-tagged and geo-referenced. Attribute information was entered through the customized Geolink user interface.

There are several benefits of collecting bus stop information in this manner. First, the position of the bus stop can be accurately recorded to within two meters of its actual real world coordinates (accuracy is dependent on satellite availability, obstructions, and other factors). Second, because attribute information is recorded directly into a digital format, errors caused by transferring handwritten notes into a digital format can be eliminated. Third, the user interface checks for errors as the data is entered (e.g., if an input value is out of range). Furthermore, the interface provides "pop-up" scroll lists for data fields that have a limited number of possible entries from which to choose.

\section{Office Processing}

Office processing involved differentially correcting the GPS coordinates, assigning a permanent stop ID, and uploading the bus stop data to a GIS for 
further processing. Without differential correction, bus stop positions can be off by more than 100 meters. Once in the GIS, the bus stop data were checked for completeness and quality. After all of the bus stops in a particular grid cell were collected, a hardcopy map was created for field verification purposes.

\section{Field Verification Procedures}

Field verification of the MARTA bus stop data was done by bringing a map graphic into the field with the associated bus stops displayed. An attribute table containing bus stop information accompanied the map graphic. Map graphics were created on a grid cell basis. This was found to be preferable to an individual route because it minimized redundant verification of road segments that had multiple routes. The purpose of the field verification was to ensure that bus stop data were as accurate as possible before being uploaded into the MARTA ITS database. Things that were looked for during the field verification were missing or misaligned bus stops, omissions in attribute fields, errors in attributes, and problems with the route alignment or the underlying street network on the hardcopy map. Corrections were made right on the hardcopy graphic and the attribute table. In some cases, it was necessary to resurvey the data using the GPS. After corrections were made, the verified bus stop information was uploaded into the MARTA ITS database.

\section{Association between Bus Stops and Route Patterns}

For the bus stop inventory data to be used in many of the ITS applications, associations between the bus stops and the route patterns must be defined. Although automated GIS tools can assist in the development of these associations, a significant manual effort is required to ensure that the associations are correct. The characteristics of bus stops complicating this task include station bus bays, near-side stops that cannot be used by buses that need to be in the left lane to make a left turn, and stops appearing on the wrong side of the road on the GIS map. More significantly, the quantity of route pattern variations contributes to the size of this task. Distinct patterns exist for route alternates, including areas only served by certain trips, abbreviated or combined weekend service, variations in AM and PM layovers, and short trips used in combination with dead- 
heads to and from garages. Additionally, the patterns and associations must be distinguished by direction (e.g., inbound vs. outbound). In the MARTA database, 143 routes consist of 770 distinct patterns, and more than 30,000 pattern associations exist for the approximately 10,000 defined bus and rail stops. These associations between bus stops and route patterns are stored in the stop-on-pattern table in the database (see Figure 1).

\section{Maintaining the Bus Stop Database}

Maintaining the bus stop database is as important as the collection and verification process for a number of reasons. First, changes in routes to accommodate new landuses and changes in the infrastructure will require moving or removing existing stops and adding new ones. Second, physical entities that make up a bus stop (i.e., the stop indicator or shelter) will require periodic maintenance. Third, because of their proximity to streets, bus stops are prone to damage from passing vehicles. In some cases, a stop that is damaged may be moved or its physical characteristics may be altered in an effort to minimize the potential for future damage from adjacent traffic (Federal Transit Administration 1996).

An out-of-date or poorly-maintained bus stop database may lead to erroneous information being given to a patron. Further, an accurate maintenance history will make it easier to predict and program future bus stop maintenance needs. Furthermore, the accuracy of the bus stop information will undoubtedly affect the various applications that require up-to-date bus stop information. One example is if the system has a bus stop annunciator capability. The announcement of a bus stop that no longer exists on a particular route would be undesirable for obvious reasons.

The maintenance of bus stop information in the MARTA ITS occurs within a GIS user interface. Figure 3 shows a sample maintenance screen. The user can select a bus stop for editing either by picking it from the GIS map display (Figure 4 ) or by selecting it from a scroll list of stop IDs. Bus stops are indicated by triangles in Figure 4. This figure also shows landmarks, bus routes, and a MARTA rail station (indicated with a round symbol). If desired, map features can be hidden to reduce clutter. 


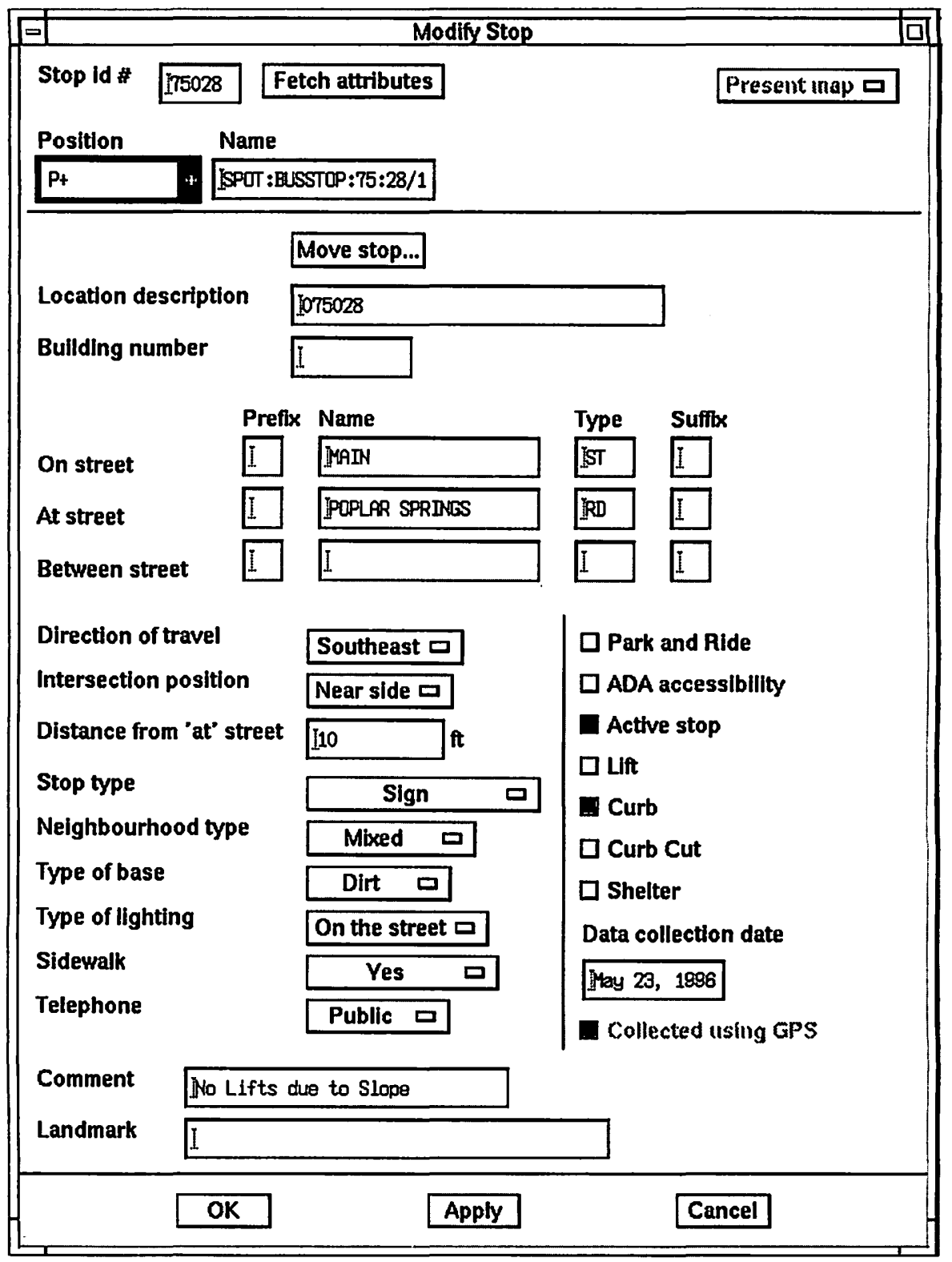

Figure 3. Bus stop maintenance screen. 


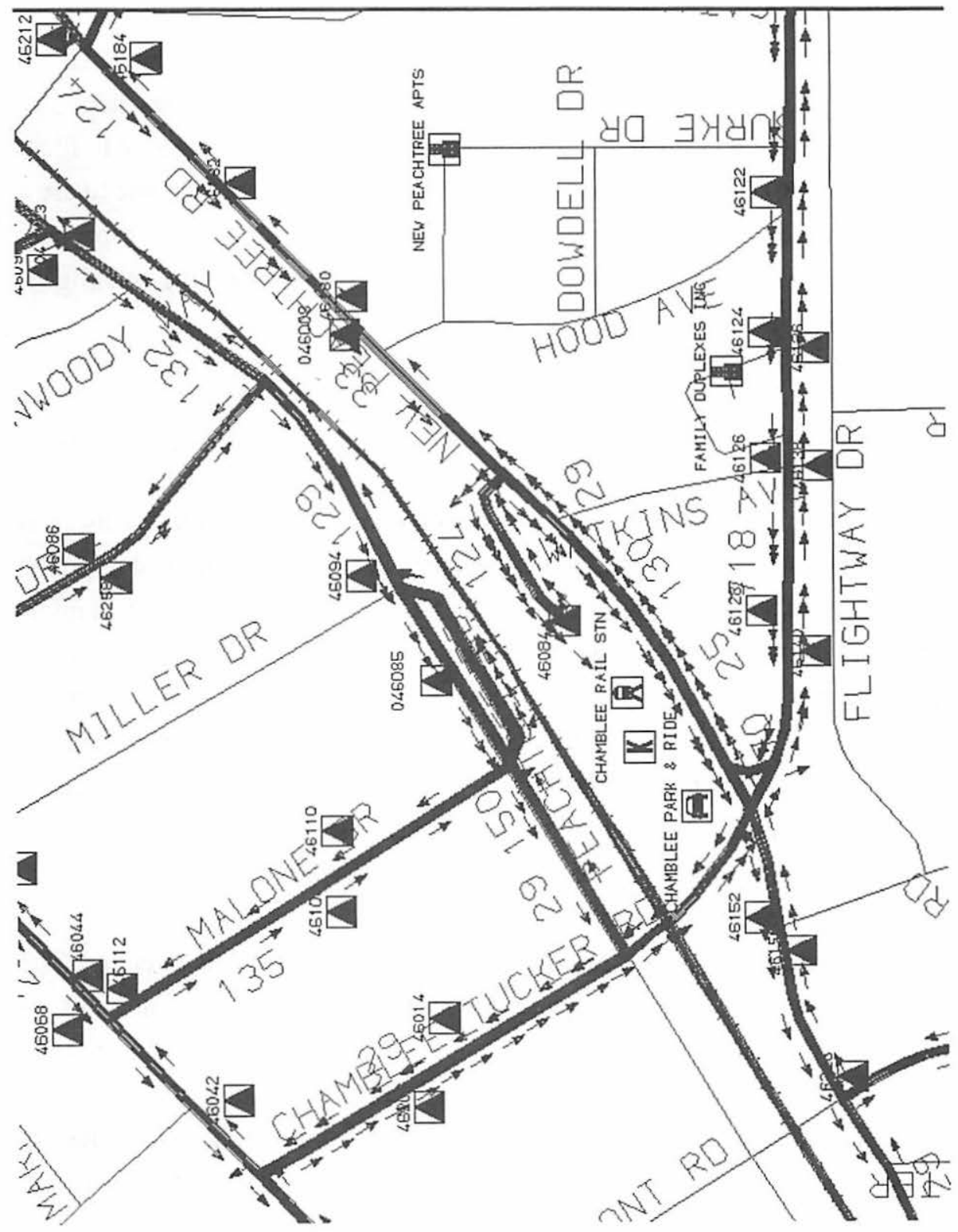

Figure 4. GIS map display. 


\section{Bus Stop Work Orders}

Figure 5 illustrates the bus stop work order form that is used by MARTA. The information on the left of the figures are attributes of the bus stop. The section to the right refers to the work to be performed as well as a spot to illustrate a bus stop. When a bus stop is being moved, it is usually preferable to use a GPS system to inventory the coordinates of the new location. This is especially important from an AVL standpoint because the AVL relies on the actual geographic coordinates of the bus stop.

\section{Conclusion}

There is a trend in the transportation industry to take advantage of evolving technologies that have had a significant impact on ITS such as GPS, GIS, and more powerful computer capabilities. MARTA has jumped on this bandwagon and, because of its recent efforts, has become a leader in ITS applied to public transportation. The main purpose of MARTA's ITS is to provide important information in a timely fashion. Whether it be trip itineraries to customer service operators, real-time bus locations to radio room operators, or bus stop announcements to MARTA patrons-the MARTA ITS is already enhancing operations on a number of fronts. Transit planning will also benefit from this system because passenger counting can be done in an automated fashion. Further, the recorded boardings and alightings can be associated with bus stops because of the AVL capability on selected bus routes.

An integral component to the MARTA ITS is the bus stop inventory. The lessons learned from MARTA's experience in creating and maintaining this inventory should be valuable to other transit agencies that are planning or are in the process of implementing an APTS. The Utah Transit Authority (UTA) has recently built a bus stop inventory that made use of some of the techniques described here. UTA is in the process of implementing an APTS that should be in place in time for the 2002 Olympics. 
TO:

DATE:

ROUTE:

FROM:

DATE REC:

I.D.H:

APPROVED:

DATE COMP:

ITS:

Answer Appropriate Block

Inbound $\square$ Outbound

On Street - plus type (e.g. Ave. Dr., etc.

At Street - plus type (c.g. Ave. Dr., etc.)

At Street near side, far side

Distance of Stop from the At Street feet (if less than 200' from corner)

Direction of Travel - N,S,E,W,NE,SE,NW,SW

Exact Corner - NE, SE, NW, SW

Mid Block -only when a bus stop is greater than $200^{\prime}$ from an intersection. AT $\square$ Opposite Address: (Block \# (over 200' from comer)

ADA Accessibility, $\mathrm{Yes}(\mathrm{Y}), \mathrm{No}(\mathrm{N})$

Sidewalk - Yes(Y), No(N), Yes but poor

Condition(YP). Yes but Short(YS).

Lift - Can lift be used? Yes $(Y)$ No $(N)$, No beciuse of incline (NI)No because of Shoulder Drop-off (NS).

Carb denotes presence of curb at bus stop Yes( $(Y)$, No(N), Yes but not lift accessible (YN)

Curb Cut - wheelchair accessible from sidewalk to street. Yes (Y), No (N), no sidewalk or curb (NA)

Telephone - None(N), Public(P), Nearby business(B)

Present Bus stop type - Sign (SGN) Post (POS), Strap (STR), MARTA Shelter (SHM), Advertisement Shelter (SHA), Pedestal Stop (PS)

Neighborhood Type - Commercial (Com) School (Sch) Industrial (IND), Mix (MIX)

Base - Type of base Concrete (Conc) or Dirt (Dirt).

Lighting - On street (S) Dedicated (D) or Poor (P)

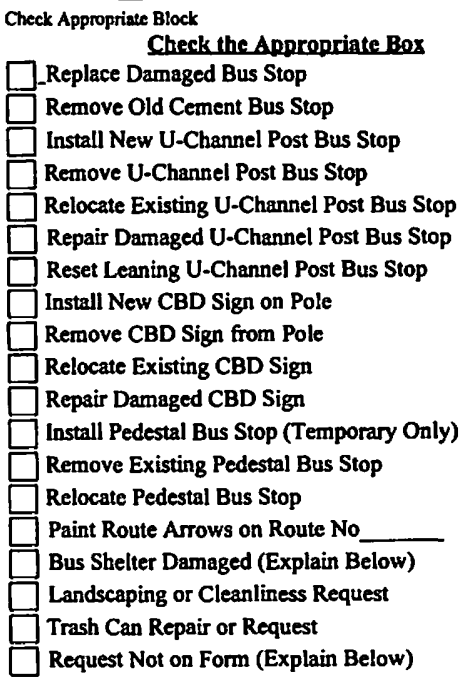

Check Appropriate Block

Check the Anpronriate Box

]_Replace Damaged Bus Stop

Remove Old Cement Bus Stop

Install New U-Channel Post Bus Stop

Remove U-Channel Post Bus Stop

Relocate Existing U-Channel Post Bus Stop

Repair Danaged U-Channel Post Bus Stop

$\square$ Reset Leaning U-Channel Post Bus Stop

Install New CBD Sign on Pole

Remove CBD Sign from Pole

$\square$ Relocate Existing CBD Sign

$\square$ Repair Damaged CBD Sign

$\square$ Install Pedestal Bus Stop (Temporary Only)

Remove Existing Pedestal Bus Stop

Relocate Pedestal Bus Stop

Paint Route Arrows on Route No

$\square$ Bus Shelter Damaged (Explain Below)

Landscaping or Cleanliness Request

Trash Can Repair or Request

Request Not on Form (Explain Below)

Pick the Appropriate street map, name the ON street, name the AT street, and spot the stop at the appropriate location on the map.

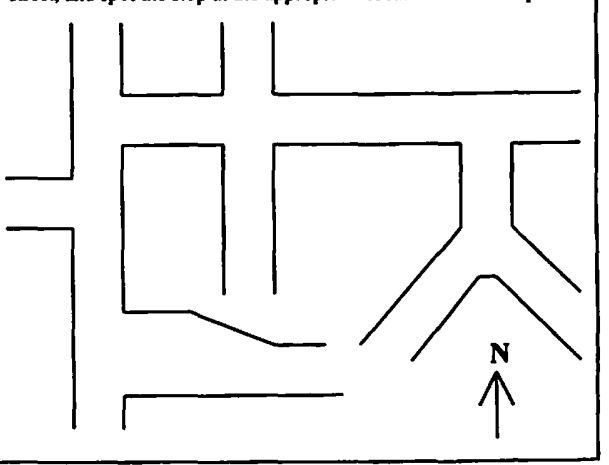

Date called

Utillties Protection Network 1-800-282-741 I Utility Location \#

A.M. P.M.

Date and Time Approved to Dig: From

A.M. P.M. To

Special Instructions:

WORK PERFORMED BY

22-8470 (Revised 1//97)

TIME:

A.M. P.M.

Figure 5. Bus stop work order form. 


\section{References}

Bricker, R.T., and C. Kemmer. 1995. Up the Pole, Down the Lane: GPS on the Utilities Circuit, in GPS World, January, Advancestar Communications, Duluth, Minnesota: $16-24$.

Casey, R.F., L.N. Labell, R. Holmstrom, J.A. LoVecchio, C.L. Schweiger, and T. Sheehan. 1996. Advanced Public Transportation Systems: The State of the Art Update '96. Report FTA-MA-26-7007-96-1. Federal Transit Administration, Washington, D.C.. Federal Transit Administration. 1996. Guidelines for the Location and Design of Bus Stops, TCRP Report 19, Transit Cooperative Research Program, Washington, D.C. Georesearch Inc. 1995. Geolink GPS/GIS Data Collection Software Manuals, Billings, Montana.

Poling, A., J. Lee, P. Gregerson, and P. Handly. 1993. Comparison of Two Sign Inventory Data Collection Techniques for Geographic Information Systems. In Transportation Research Record 1429, TRB, National Research Council, Washington, D.C.: $36-39$.

Trimble Navigation Ltd. 1995. Pathfinder Basic Plus User's Manual, Sunnyvale, CA.

\section{About the Authors}

Wayne Sarasua is an Assistant Professor in the School of Civil and Environmental Engineering at Georgia Tech. His research interests focus on the application of spatial data analysis technologies in transportation.

Robert Awuah-Baffour is an Assistant Professor in the Civil Engineering Department at Bradley University. He recently finished his doctorate in the School of Civil and Environmental Engineering at Georgia Tech. His doctoral thesis explored the use of a specialized attitude GPS unit to collect roadway grade and cross slope information simultaneously.

MARK Fawley is a Project Manager for TRW. His expertise is in large software system development and integration and relational database design.

Carlton Byars is in charge of bus stop maintenance at MARTA. He is responsible for the upkeep of all GIS bus-stop-related databases including landmarks, timepoints, and announcement points.

JefFery OrTon is the GIS Coordinator with the Utah Transit Authority. He is in charge of maintaining the databases that support UTA's GIS. 